\title{
Basic Experimental Studies on Coconut Shell Charcoal Ash in Modified Bitumen
}

\author{
Dr. S. Suchithra ${ }^{1, a^{*}}$, S. Madhankumar2,b, M. GowshicPrasanna ${ }^{2, c}$, \\ V. Nandhakumar ${ }^{2, \mathrm{~d}}$ and S. Jayashree ${ }^{3, \mathrm{e}}$ \\ ${ }^{1}$ Associate Professor, Department of civil enginerring, Kongu Engineering College, Perundurai, \\ Erode, Tamilnadu, India \\ ${ }^{2}$ U.G Students, Department of civil engineering, Kongu Engineering College, Perundurai, Erode, \\ Tamilnadu, India \\ ${ }^{3}$ P.G Student, Department of civil engineering, Kongu Engineering College, Perundurai, Erode, \\ Tamilnadu, India \\ a* suchithra@kongu.ac.in, ${ }^{\mathrm{b}}$ madhankumarvedha@gmail.com, ${ }^{\mathrm{c}}$ gowshicprasannakec57@gmail.com \\ , dvenkateshnandhakumar@gmail.com, e jayashreesiva22@gmail.com
}

Keywords: Bitumen, Aggregate, Coconut Shell Charcoal, Filler, Marshall Test

\begin{abstract}
For reducing the cost in bitumen roads and also increasing the efficiency of bituminuous roads, varieties of materials are used for improving the road by using coconut shell charcoal ash as fillers in the flexible pavement. In the literature work, the main descriptive of the work is to compare the results with different percentages of coconut shell charcoal ash in bitumen. The Properties of the coconut shell charcoal possesses are resistance to breaking the materials, absorbing the heat, moisture content of surface, grading, heating and synthetic resin glues which is important for pavement of bitumen roads. Therefore, its stability of Marshall stability test and flow value in Marshall stability and air void ratio are obtained. So that it can be compared with different modified percentage as $4.5 \%, 5 \%, 5.5 \%$ and $6 \%$ in test on Bitumen. From this test we can establish so that it can be useful as a substitute as a coconut shell charcoal ash for improving the strength, quality and durability of bitumnious road. For carrying out these experiments, Marshall stability test is used for obtaining better results for normal mix and modified mix for the bitumen.
\end{abstract}

\section{Introduction}

A proper mixture of bitumen and aggregates were heated, which is laid on the road and compacted well on the granular layer bed to form a flexible pavement. A flexible pavement consists of a base course, a sub base course and a bituminous surface course. Base course of a flexible pavement is the one which lies below the surface course or wearing course and above thesub base course. And this layer provides some additional load distribution, drainage layer and frost resistance in flexible pavement. Base course are usually constructed out of Hot Mix Asphaltand as well as aggregate [1].

Coconut shell charcoal ash is a product of agriculture obtained by burning coconut shells in a limited supply of oxygen. It is widely known for its use as a domestic and industrial fuel. Coconut Shell Charcoal Ash as filler material can be used as addition of different percentages in Bitumen for the construction of flexible pavement[1].

Coconut shell is the agricultural waste product and the coconut fiber can be easily removed if the coconut shell fiber is allowed for sun-dry. In the coconut shell removed waste things and washed unwanted waste materials. To change some properties of charcoal, the coconut shells can be subjected to the heating process for five minutes at the temperature of 400 to $450^{\circ} \mathrm{C}$ using furnace[1]. Coconut shell charcoal after heating at certain temperature and allowed them to cool 
down the temperature before doing its crushing the coconut shell charcoal. Coconut shell charcoal ash grinded out after the cooling process is over and crushed them manually or physically. Coconut shell charcoal ash was sieved in sieve size passing through $2.36 \mathrm{~mm}$ sieve and retained in $0.075 \mathrm{~mm}$ sieve. Coconut Shell charcoal Ash was then weighted 4.5\%, 5\%, 5.5\%, and 6\% by weighting the bitumen for testing the bitumen conducted.

\section{Methodology}

Literature review paper was studied and the sample was collected from agricultural waste and the material properties of Bitumen, Coarse aggregate and Coconut shell charcoal was collected. After that aggregate tests and experimental work on bitumen are done in the laboratory and after that discussions and conclusion was completed.

\section{Material properties}

Bitumen

- It is obtained from coal and tar. The properties and chemical composition of coal tar and bitumen are similar like, both are black in color and sticky. Heating the coal at very high temperature give coal tar and it is the by-product of coke and gas[2].

- The bitumen is used as a binding agent for the road construction. It has been produced by asphalt replacement of about $30-70 \%$. The bitumen was used in the highway department[2].

Aggregate

- An aggregate is used for construction purpose, which provides greater strength for the construction. The aggregates can give good characteristic performance for giving strength. About $95 \%$ of the mixture by weight is covered by aggregates[2]. The good physical property and good quality of the aggregates ensures the good pavement. The aggregate was using $10 \mathrm{~mm}$ graded aggregate and $20 \mathrm{~mm}$ grade aggregate to use for mix in the bitumen.

\section{Coconut shell charcoal}

1. Coconut shell charcoal gives the strength and high property for the other fillers and dueto its low specific weight and hardness[3].

2. It shows property of high modulus.

3. It has high resistance to different weather as High lignin content and it is suitable forconstruction purpose[3].

4. It has good durability and abrasion resistance Characteristics in the charcoal ash[3].

5. It has low Cellulose Content.

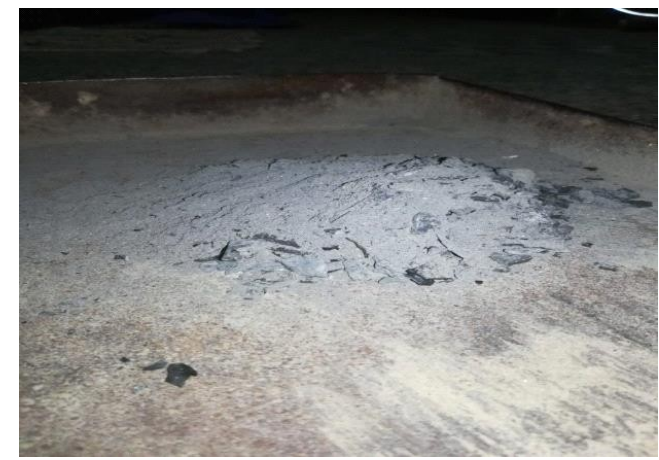

Figure 1. Coconut shell charcoal ash 


\section{Experimental work on aggregates}

Specific gravity test on Coarse aggregate

This test on coarse aggregate in specific gravity and it is used to check the quality and strength of the material. The aggregates having high specific gravity possess greater strength compared that of the aggregates having low specific gravity. The strength was identified helps with the specific gravity test. The aggregates used for construction work should have the specific gravity about 2.6 to 2.9. The specific gravity of the aggregates obtained as 2.87 , hence it is acceptable[4]. The figure 2 consists of Specific gravity test on coarse aggregate.

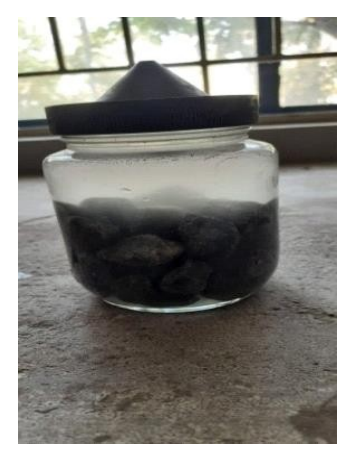

Figure 2.Specific Gravity test on coarse aggregate

Water absorption test on coarse aggregate

This test gives an idea for checking the quality and different strength of rock. The aggregates having more water absorption and having more porous in nature and based on the strength, impact and hardness and found to be acceptable. The aggregates may have water absorption values between 1.0 to 2.0 percent for surface dressing. As we done the water absorption test on coarse aggregate is $2 \%$ and it can be used for construction work purpose[4]. The figure 3 consistsof Water absorption test on coarse aggregate.

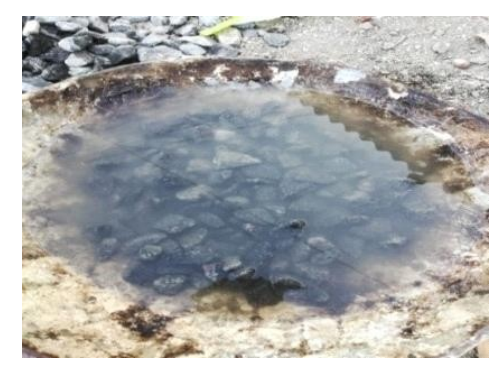

Figure 3. Water absorption test on coarse aggregate

Sieve analysis \& Fineness modulus test on coarse aggregate

In Sieve analysis test and fineness modulus test of coarse aggregate and the sieve sizes are arranged in the order such as $80 \mathrm{~mm}, 63 \mathrm{~mm}, 50 \mathrm{~mm}, 40 \mathrm{~mm}, 31.5 \mathrm{~mm}, 25 \mathrm{~mm}, 20 \mathrm{~mm}, 16 \mathrm{~mm}$, $12.5 \mathrm{~mm}, 10 \mathrm{~mm}, 6.3 \mathrm{~mm}$ and $4.75 \mathrm{~mm}$. The fineness modulus value is calculated by using (Cumulative percentage retained / 100). From the graph we can follow some specifications. Straight curve implies uniformly graded aggregates which can be used in base course. S curve implies well graded aggregates which can be used in drainage layers and sub base course. Combination of straight and S curve implies gap graded aggregates which can be used in sub base. 
If none of the above conditions occur, aggregate may be graded as poorly graded[4]. The figure 4 consists of Sieve Analysis test on coarse aggregate.

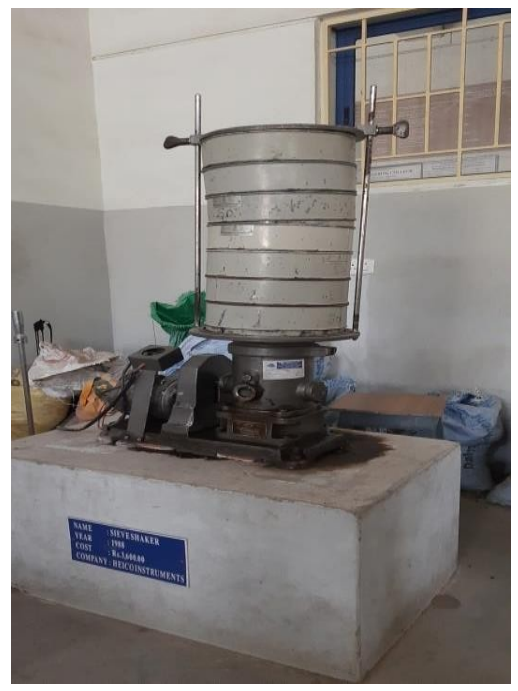

Figure 4. Sieve analysis test on coarse aggregate

Impact value test on coarse aggregate

Toughness means the property of a material to resist the sudden load. Since the movement of vehicle provides impact load on the aggregates, it is necessary to determine the impact value i.e., crushing value of aggregates. The impact value of aggregates is based on the sudden break applied by the vehicle and the load of the vehicle which acts as the compressive load on the aggregates, due to sudden break. The impact value of aggregates should not exceed $30 \%$ and $45 \%$ for the wearing course and base course respectively as per IS 2383-1963[5]. Hence the given aggregate can be used for subgrade, base and surface course. As we done the aggregate impact value of coarse aggregate is $8.54 \%$.The type of pavement where the aggregate can be used is wearing course and Base course. The figure 5 consists of Impact value test on coarse aggregate.

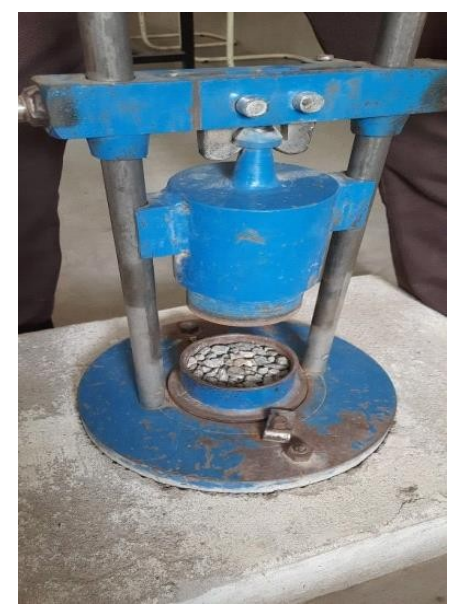

Figure 5.Impact value test on coarse aggregate 


\section{Crushing value test on coarse aggregate}

The crushing value of coarse aggregate it gives a relative measure and it is crushing an aggregate under gradually applying compressive load. This coarse aggregate gives more strength for the road construction. Aggregate with lower crushing value and it give long service life to the road. The broken coarse aggregate or crushed aggregate can be used for the highway. The aggregate used in the road construction should be strong bonder roller traffic. According to IS: 9376-1979 the crushing value of good quality aggregates to be used in base course and surface course shall not exceed $45 \%$ and shall not be less than $30 \%$ respectively[6]. As we done the crushing strength of given aggregate sample is $6.14 \%$. The figure 6 shows crushing value test on coarse aggregate.

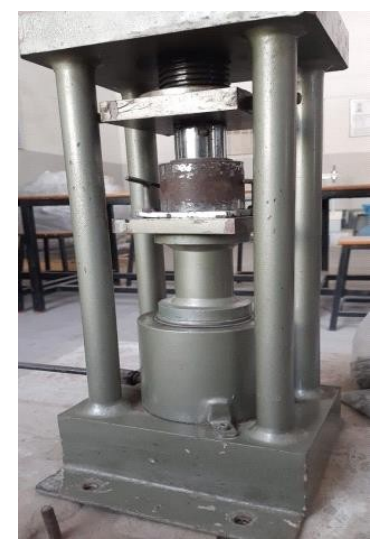

Figure 6. Crushing value test on coarse aggregate

Attrition value test on coarse aggregate

Attrition test is a combination of the impact test and the abrasion test, because the stones are impacted due to the drop during rotation of the cylinder and the stone dust formed acts as an abrasive between the metal pieces. This property is quite essential in a road stone to be used in water bound macadam road and bitumen painted roads. Aggregate attrition value is below $2 \%$ and the quality is very good, the value is 2 to $2.5 \%$ and the quality is good, the value is 2.5 to $3.1 \%$ and the quality is fairly, the value is 3.1 to $4.0 \%$ and the quality is poor and the value is

over $4 \%$ and the quality is very poor ${ }^{[9]}$. As we done the Attrition aggregate test and the value is $1.1 \%$ and the quality of the aggregate is very good. The figure 7 shows attrition value test on coarse aggregate.

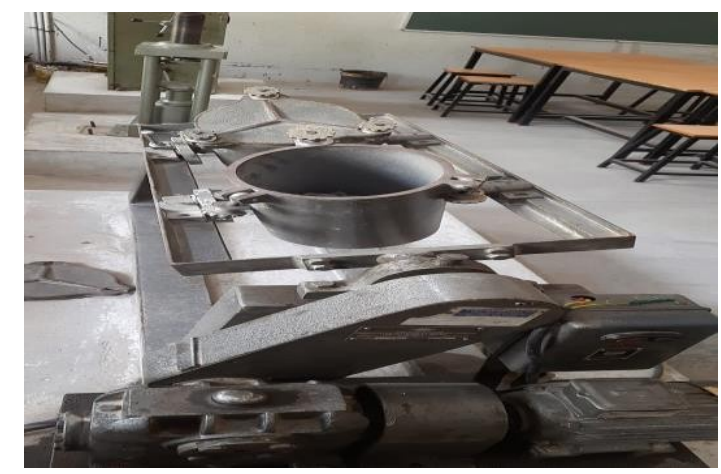

Figure 7.Attrition value test on coarse aggregate 


\section{Abrasion value test on coarse aggregate}

Abrasion Value of the aggregates is determined in order to determine their resistance against wearing due to the movement of traffic. When fast moving traffic fitted with pneumatic tyres on the wheels move on the road, the soil particles present between the road surface and the tyres cause abrasion of the road surface. As per IS: 10070 - 1982 the abrasion value should not be more than $30 \%$ and $50 \%$ for wearing surfaces and concrete other than wearing surface respectively[7]. As we done the abrasion test the value is $0.57 \%$ and it can be used for wearing courses and for concrete. Abrasion testing machine is shown in figure 8 on coarse aggregate.

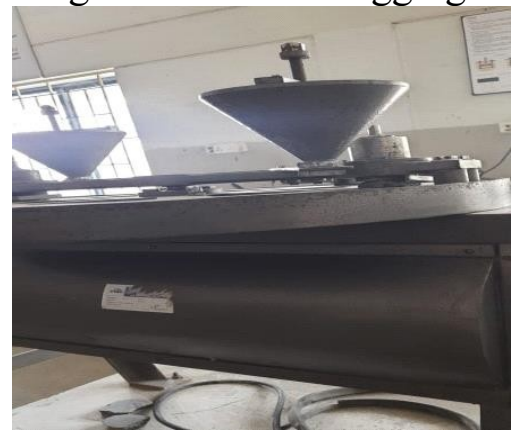

Figure 8 . Abrasion value test on coarse aggregate

\section{Flakiness index of coarse aggregate}

The aggregates are flaky and are not desirable because the large number of flaky aggregates creates more voids, which in turn requires large amount of water and fine materials for the same workability, since such shapes offer more surface area for lubrication. It also tends to harm durability and the particles tend to causing limitations. Flakiness index or elongation index is the weight of flaky of elongated particles measured as percentage of the total weight of the sample. Flakiness index in excess of 35 to 40 percent is considered undesirable. No limits for elongation index are known to have been prescribed as yet. According to IS: 383-2016 the flakiness index should not exceed $40 \%$. As we done the flakiness index of the aggregates the value is $1.13 \%$. The figure 9 consists of Flakiness index of coarse aggregate [8].

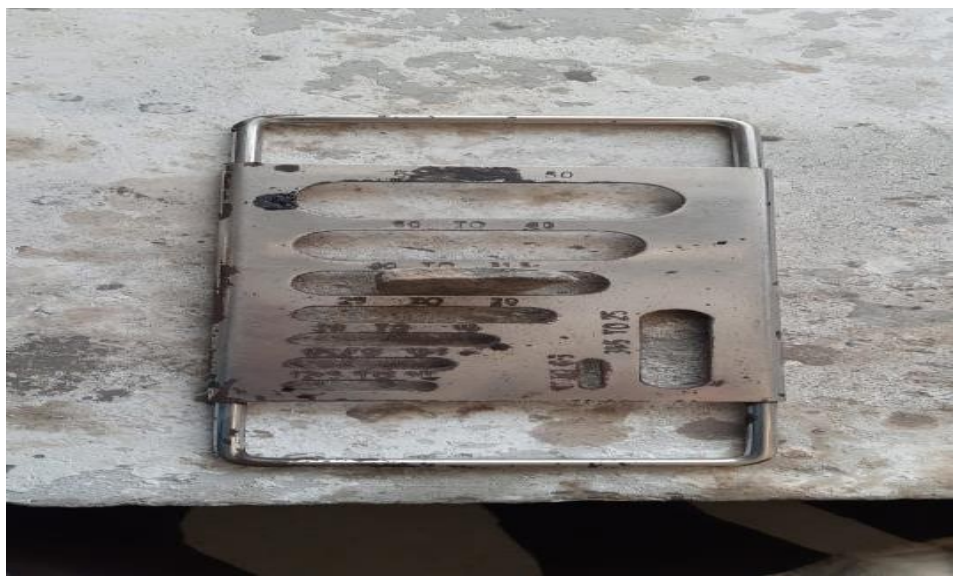

Figure 9.Flakiness index of coarse aggregate 


\section{Elongation index of coarse aggregate}

The elongation index of coarse aggregate is the percentage by weight of particles whose greatest dimension or length is greater than 1.8 times their mean dimension. This test is not applicable to aggregates of size smaller than $6.3 \mathrm{~mm}$. According to IS: 383-2016 the Elongation index should not exceed $40 \%[8]$. As we done the Elongation index of the aggregates the value is $20.26 \%$. The figure 10 consists of Elongation index of coarse aggregate.

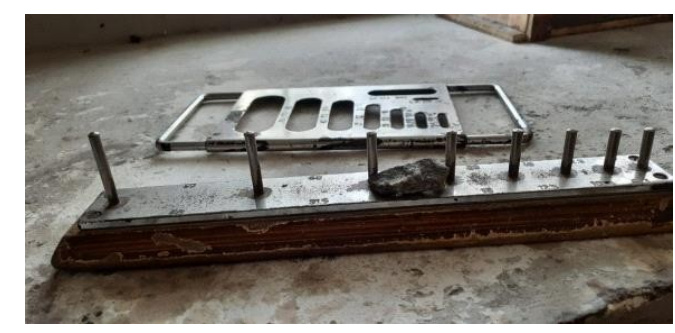

Figure 10.Elongation index of coarse aggregate

\section{Experimental work on bitumen}

Specific gravity test on bitumen

A knowledge of the correct specific gravity of bituminous materials have mainly two application convert the specified bitumen content by weight of volume basis when the binder is measured by volume is necessary to know the coefficient of expansion or the specific gravity values at different temperatures. Second, the specific gravity is useful to identify the source of a bituminous binder. Pure bitumen has a specific gravity in the range from 0.97 to $1.02[4]$. Thus it is possible for a qualitative estimation of mineral impurity in bitumen. Table 1 gives the specific gravity values of different samples. The figure $11 \& 12$ consists of Specific gravity test on Bitumen.

\section{Penetration test on bitumen}

To determine the consistency, this test is conducted on the bitumen. It is expressed as the distance in tenths of a millimeter that a standard needle it penetrates through vertically in to

specimen of penetration test of a specified temperature. Penetration values of different proportions of coconut shell charcoal ash in bitumen. The penetration test followed by IS code 1203-1978. The figure 13 \& 14 consists of penetration test on bitumen [9]. Table 2 gives the corresponding values for different samples.

Table 1 specific gravity values of different samples

\begin{tabular}{|l|c|}
\hline \multicolumn{1}{|c|}{ Test samples } & Value \\
\hline $100 \%$ of Bitumen & 1.1 \\
\hline Bitumen $+4.5 \%$ Coconut Shell Charcoal ash & 1.05 \\
\hline Bitumen $+5 \%$ Coconut Shell Charcoal ash & 1.06 \\
\hline Bitumen $+5.5 \%$ Coconut Shell Charcoal ash & 1.08 \\
\hline Bitumen $+6 \%$ Coconut Shell Charcoal ash & 1.1 \\
\hline
\end{tabular}




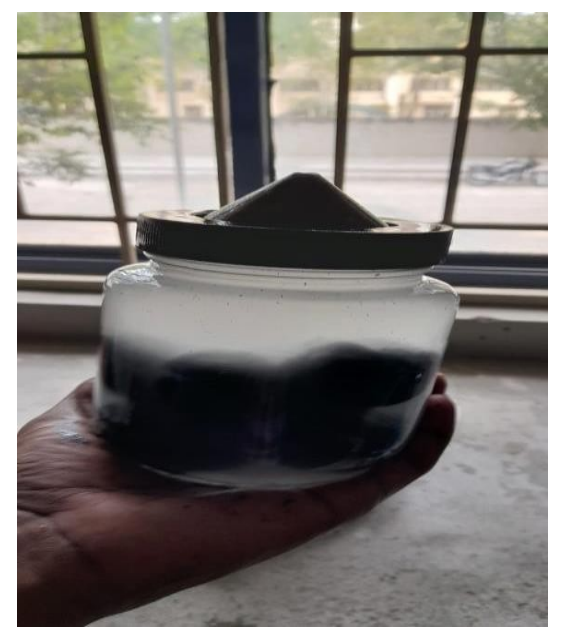

Figure 11.Specific gravity test on bitumen

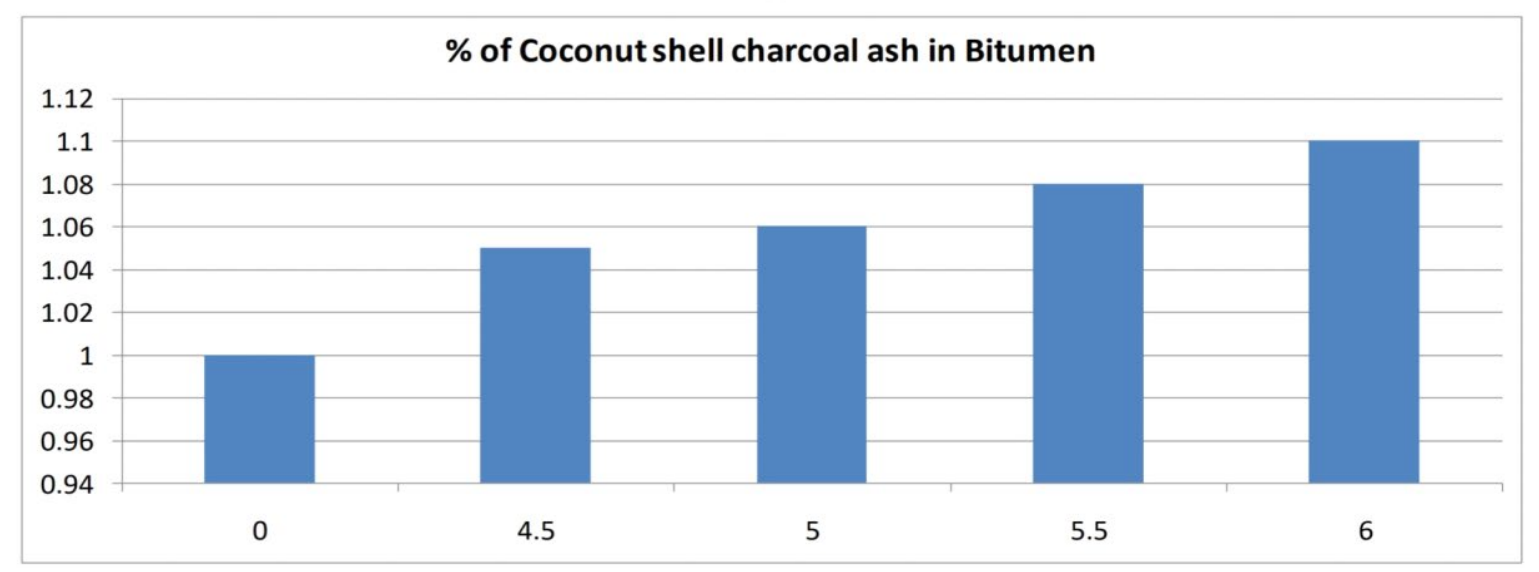

Figure 12.Specific gravity test on bitumen

Table 2 Penetration test values of different samples

\begin{tabular}{|l|c|}
\hline \multicolumn{1}{|c|}{ Test samples } & Value \\
\hline $100 \%$ of Bitumen & 70 \\
\hline Bitumen $+4.5 \%$ Coconut Shell Charcoal ash & 83 \\
\hline Bitumen $+5 \%$ Coconut Shell Charcoal ash & 91 \\
\hline Bitumen $+5.5 \%$ Coconut Shell Charcoal ash & 95 \\
\hline Bitumen $+6 \%$ Coconut Shell Charcoal ash & 99 \\
\hline
\end{tabular}




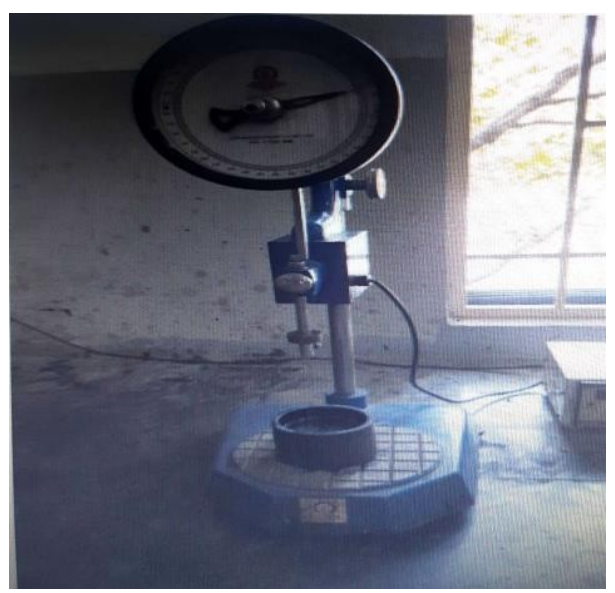

Figure 13.Penetration test on bitumen

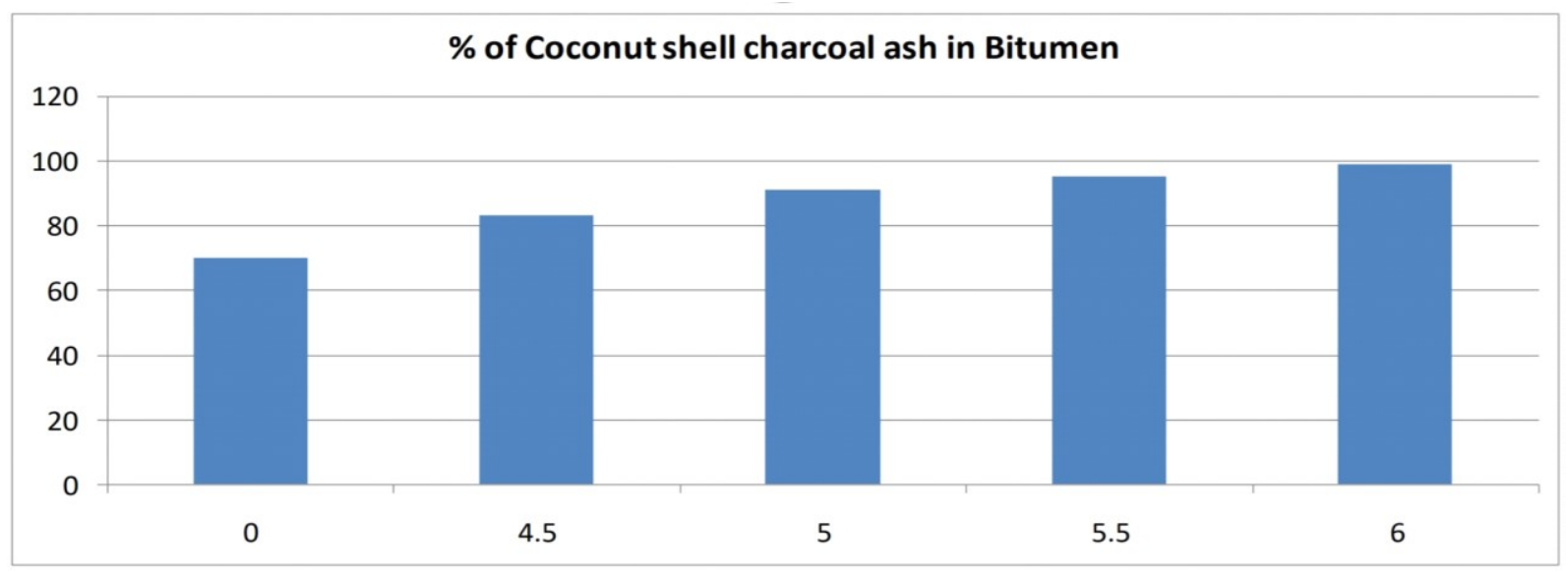

Figure 14.Penetration test on bitumen

\section{Conclusion}

From the test results, it is concluded that by using coconut shell charcoal ash as a filler materialin bitumen for the road construction shall be $0 \%, 4.5 \%, 5 \%, 5.5 \%, 6 \%$. Laboratory tests were conducted for the modified bitumen and compared with the 100\% bitumen test results. The addition of coconut shell ash in the bitumen improves the properties of bitumen in all aspects, which helps to improve the lifespan of the bitumen. After analyzing the tests, it has been inferenced that the results of modified bitumen have more workability than 100 percent bitumen. From the properties of all modified bitumen, we conclude that the values are increasing and giving better strength and has better to be used in highway construction. 


\section{References}

[1] M. Mohan, K.M. Hussaina, I. Easa, M.K. Faisal, M.A.K. A, Bitumen Modification Using Crumb Rubber and Partial Replacement of Fine Aggregates Using Coconut Shell, Int. J. Innovative Research. Managem. Eng. Technol. 4 (2019).

[2] R.P. Jaya, M.R. Hainin, K.A. Masri, Performance of Charcoal Coconut Shell Ash in the Asphalt Mixture under Long Term Aging, Int. J. Recent Technol. Eng. 8 (2019) 383-387. https://doi.org/10.35940/ijrte.C1010.1183S319

[3] S. Dung Dung, Assessment of the Suitability of Coconut Shell Charcoal As Filler in Stone Matrix Asphalt, (2014).

[4] S.K. Dr.Khanna, C.E.. Dr.Justo, A. Dr.Veeraragavan, Highway Engineering, 2015.

[5] IS 2386- Part III, Method of Test for aggregate for concrete. Part III- Specific gravity, density, voids, absorption and bulking, Bur. Indian Stand. New Delhi. (1963) (Reaffirmed2002).

[6] M. Kisan, S.Sangathan, J. Nehru, S.G. Pitroda, मानक, (1979).

[7] M. Kisan, S. Sangathan, J. Nehru, S.G. Pitroda, मानक, (1982).

[8] Bureau of Indian Standards (BIS), Concrete Mix Proportioning- Guidelines, Bur. IndianStand. Second Rev (2019) 1-40. https://doi.org/10.1201/9780429285196-1

[9] IS: 1201-1220, Indian standard methods for testing tar and bituminous materials., Bur.Indian Stand. (1978) 1st Revision. 